\title{
The Impact of Flipped Learning on Engagement with the Learning Process in Pre-Licensure BSN Students
}

\author{
Carlo Guy Parker* \\ School of Nursing, University of Northern Colorado, USA
}

*Corresponding author: Carlo Guy Parker, School of Nursing, University of

Northern Colorado, USA.

Received Date: October 10, 2020

Published Date: November 09, 2020

\begin{abstract}
The U.S. faces a nursing shortage and contributing to that shortage are high attrition rates for nursing students and RNs. One solution to decrease attrition is to increase student engagement with the learning process. One way to increase engagement is changing pedological methods. This study looks at the impact of a novel pedological method, flipped learning on student engagement. This study compares the flipped method to the tradition lecture method. Student engagement was measured with a valid and reliable tool, the SCEQ. The study design was quantitative, experimental and contained repeated measures. BSN students ( $\mathrm{N}=131)$ were either instructed with the flipped method or traditional method. The SCEQ was reliable and showed that there was an increase in student engagement in the flipped group $(p<.05)$ and no change in the tradition lecture group ( $p=.315)$. Nurse educators should consider implementation of flipped learning as part of an effort to decrease nursing student attrition.
\end{abstract}

\section{Background}

The United States faces a nursing shortage that is projected to worsen in the next decades as the baby boomers age and many nurses retire [1]. According to the American Association of Colleges of Nursing (2017) [2] there is a limited educational capacity to train new nurses driven by a lack of qualified faculty and clinical space. This resulted in 64,067 qualified nursing school applicants being rejected by nursing programs in 2016-2017. In addition, there is high attrition rate among nursing students prior to graduation, 20 to $50 \%$ [3] and high attrition by Registered Nurses, 10-26\%, once in practice. These two factors, limited capacity and high attrition rates mean that it is imperative that nurse educators try to minimize student nurse attrition to maximize the number of new nurses produced and retained in nursing. The literature suggests that student engagement with the learning process may play a role in the problem of attrition and retention in nursing. Increasing engagement in students and RNs with the learning process offers the potential to address the issues mentioned here [4].

The construct being measured in this study was nursing student engagement in the learning process. Student engagement has been defined by Kuh (2009) [5] as the "quality of effort and involvement in productive learning activities" by students. Students who are engaged in their course work have been shown to achieve better grades, more personal satisfaction with their education, higher institutional retention and increased graduation rates $[6,7]$. In addition, critical thinking, considered a key ability required to be successful as a nursing student and as a practicing registered nurse, is linked positively in the literature to student engagement [8]. The lack of nursing student engagement is correlated with course failure and dropping out of college [9]. There is evidence that engagement in nursing students is lower than in other healthcare 
professions [10]. In addition, low nursing student engagement may indicate future problems with hospital retention related to clinical performance of registered nurses [4].

One way to increase student engagement, which is supported in the literature, is to change the pedogeological method utilized to deliver the content. To increase student engagement in the learning process changing the content deliver method to the flipped classroom has been one approach used [11-13]. The change was to depart from the standard lecture method utilized in most classrooms and utilized a flipped learning approach [14]. The Flipped classroom approach changes the way instruction is delivered to the students. Lectures are video recorded for the students to view prior to coming to class. The students work on the lower level concepts like understanding and meaning prior to class. In class the instructor actively engages in the material with the students, focusing on the higher-order activities like applying, analyzing, evaluating and creating in a team-based, active environment. This increases meaningful contact time between the student and instructor and contact between students. This active learning process created by the flipped classroom promotes critical thinking [15-17]. Students come to class and apply the material to real word situations to develop real solutions the problems they see daily as student nurses. The traditional method refers to lecture with supporting audio-visual presentations and tests.

\section{Aim}

This research was conducted to determine if using the flipped instructional method compared to traditional lecture influences nursing student engagement in learning. The research question was, will the flipped classroom method, when compared to the traditional lecture method influence the level of nursing student engagement in the learning process?

\section{Methods}

Approval for the study was obtained by the Institutional Research Board prior to any data collection. A quantitative experimental repeated measures design was utilized to determine the effect of class delivery method on nursing student engagement. Engagement was measured using the Student Course Engagement Questionnaire (SCEQ) [18]. The instrument is in the public domain and not copyrighted. SCEQ is a valid and reliable 23-item Likert tool. The tool asks subjects to rate their learning efforts and selfmotivation related to their class work on the continuum of: very characteristic of me, characteristic of me, moderately characteristic of me, not really characteristic of me, not at all characteristic of me. The SCEQ has been used to measure both undergraduate and graduate student's levels of engagement across multiple disciplines, in US populations as well as many international studies and found to be valid and reliable. To determine the appropriate sample size a power analysis was performed utilizing $G^{*} 3$ Power $[19,20]$. The results indicated that a sample size of 60 for each group would be sufficient, a total of 120 subjects.
Purposive sampling was utilized to recruit subjects for this study. The sample was recruited from the undergraduate students (BSN) at a single university in the western USA. The study was conducted on 4 different cohorts of BSN nursing students. Students were recruited and provided detailed information about the study. Volunteers who consented completed a paper and pencil SCEQ. Nursing students $(\mathrm{N}=131)$ in their junior year taking a nursing research and evidence-based nursing class participated in this study. All subjects had the same faculty member as an instructor. Within the sample there were two groups. The first group $(n=64)$ received instruction in the traditional method, lecture. During that time (1 year) a flipped class version of the course was developed, vetted and approved through the curriculum process. The 2 nd group $(n=67)$ received instruction by the flipped classroom method. The questioner was completed at the beginning of the class and at the end of the class. None of the students reported having experienced a flipped class prior to this study. The sample demographics in the flipped group was $93.4 \%$ female, 91\% Caucasian. The average age was 26 years old. The demographics for the traditional lecture method was similar, 92.3\% Female, 91.4\% Caucasian.

\section{Results}

A dependent groups t-test was used to analyze the data (SPSS version 20). Reliability of the SCEQ was checked with Cronbach's alpha for group one, traditional lecture $(\alpha=.69)$ and Group two, the flipped classroom $(\alpha=.74)$. There was a significant (two-tailed) difference between student engagement levels $(\mathrm{p}<.05)$ after taking a flipped class. The mean SCEQ score after $(M=4.28, S D=.72)$ was higher than the score before the flipped class ( $M=4.02, \mathrm{SD}=.89) ; \mathrm{t}$ $(66)=-2.59$. The group that took the traditional lecture class did not show a significant change in engagement levels $(p=.315)$.

\section{Conclusions}

The results of this study are consistent with what the literature has demonstrated about student engagement with the learning process and Flipped learning as a pedological method of content delivery. Educators in both the academic and clinical setting should consider using the flipped classroom to increase student and RN engagement in the learning process. Further studies need to be conducted to determine if flipped leaning and increased engagement are correlated with higher level of knowledge and skill retention, as well a workforce retention of RNs, and retention of BSN students. There are limitations to this study. The study was conducted at a single site, only Nursing Research and EBP classes studies. In addition, the sample is not diverse. This study should be replicated with a larger, more diverse sample as well as be a multisite study. The flipped method should also be compared to fully on online methods of content delivery. The study should be conducted with a diverse group of practicing $\mathrm{RN}$ to see if the increase in engagement is present in that population because of flipped learning pedagogy. It is imperative that nurse educators employ evidence-based pedological strategies as part of a comprehensive effort to decrease 
nursing student and RN attrition rates. This approach should help the nursing shortage by reducing attrition.

\section{Acknowledgement}

None.

\section{Conflict of Interest}

Author declare no conflict of interest.

\section{References}

1. National League for Nursing (2018).

2. American Association of Colleges of Nursing (2017) Nursing shortage fact sheet.

3. Mooring QE (2016) Recruitment, advising, and retention programsChallenges and solutions to the international problem of poor nursing student retention: A narrative literature review. Nurse Educ Today 40: 204-208.

4. Rudman A, Gustavsson JP (2012) Burnout during nursing education predicts lower occupational preparedness and future clinical performance: A longitudinal study. Int J Nurs Stud 49(8): 988-1001.

5. Kuh GD (2009) The national survey of student engagement: Conceptual framework and empirical foundations. New Directions for Institutional Research 141.

6. Kuh GD (2003) The national survey of student engagement: Conceptual framework and overview of psychometric properties. Indiana University Center for Postsecondary Research.

7. Wefald AJ, Downey RG (2009) Construct dimensionality of engagement and its relation with satisfaction. J Psychol 143(1): 91-111.

8. Skinner EA, Pitzer JR (2012) Developmental dynamics of student engagement, coping and everyday resilience. In: SL Christenson, C Reschly and C Wylie (Eds.). Handbook of research on student engagement. New York, USA.
9. Bruce M, Omnipotent M, Gustavsson P (2010) Active and emotional student engagement: A nationwide, prospective, longitudinal study of Swedish nursing students. Int J Nurs Educ Scholarsh 7(1): Article 14.

10. Popkess AM, McDaniel A (2011) Are nursing students engaged in learning? A secondary analysis of data from the National Survey of Student Engagement. Nurs Educ Perspect 32(2): 89-94.

11. James AJ, Chin CKH, Williams BR (2014) Using the flipped classroom to improve student engagement and to prepare graduates to meet maritime industry requirements: a focus on maritime education. WMU Journal of Maritime Affairs 13: 331-343.

12. McLaughlin, Jacqueline E, Griffin LM, Esserman DA, Davidson CA, et al. (2013) Pharmacy student engagement, performance, and perception in a flipped satellite classroom. Am J Pharm Educ 77(9): 196.

13. Roehl A, Reddy SL, Shannon GJ (2013) The flipped classroom: An opportunity to engage millennial students through active learning. Journal of Family and Consumer Sciences 105(2): 44-49.

14. Flipped Learning.

15. Espey M (2018) Enhancing critical thinking using team-based learning. Higher Education Research \& Development 37(1): 15-29.

16. Kusumoto Y (2018) Enhancing critical thinking through active learning. Language Learning in Higher Education 8(1): 45-63.

17. Styers ML, Van Zandt PA, Hayden KL (2018) Active learning in flipped life science courses promotes development of critical thinking skills. CBE Life Sci Educ 17(3): ar39.

18. Handelsman MM, Briggs WL, Sullivan N, Towler A (2005) A measure of college student course engagement. Journal of Educational Research 98: 184-191

19. Faul F, Erdfelder E, Lang AG, Buchner A (2007) G*Power 3: A flexible statistical power analysis program for the social, behavioral, and biomedical sciences. Behavior Research Methods 39(2): 175-191.

20. National Survey of Student Engagement (2015). 